\title{
Epidemiological and clinical correlates of chlamydial infection of the cervix
}

\author{
O P ARYA, * H MALLINSON, + AND A D GODDARD \\ From the *University Department of Venereology, Royal Liverpool Hospital; the †Regional Public \\ Health Laboratory; and the $₹$ Computer Laboratory, University of Liverpool, Liverpool
}

SUMMARY Of 474 women studied to identify epidemiological and clinical correlates of chlamydial infection of the cervix, Chlamydia trachomatis was isolated from $158(33 \cdot 3 \%)$ of all women, from $48 \cdot 3 \%$ of those infected with Neisseria gonorrhoeae, from $43 \%$ of the sexual consorts of men with nongonococcal urethritis, and from $74 \%$ of those whose consorts were also infected with $C$ trachomatis. $C$ trachomatis was the sole pathogen found in 58 women. Age, marital state, occupation, past history of gonorrhoea, menstrual state, and symptoms had no predictive value. The isolation of $C$ trachomatis was significantly associated with $N$ gonorrhoeae, the use of oral contraceptives, cervical ectopy, cervicitis, and last sexual exposure more than one week previously. Except for three patients, none of the criteria alone or in combination was reliable enough to predict with acceptable accuracy that the 30 chlamydia-positive women among the 191 who were not infected with $N$ gonorrhoeae and whose consorts were not known to have urethritis harboured chlamydia.

\section{Introduction}

Gonorrhoea and non-specific genital infection are now the commonest sexually transmitted diseases. Both are easier to detect in men than in women; hence their incidence in men would probably be a fair reflection of the true situation. In the year ending 31 December 1978, 35366 male cases of gonorrhoea and 78298 male cases of non-specific genital infection were diagnosed at the hospital clinics in England. ${ }^{1}$ If, as is now generally accepted, half of these non-specific genital infections were due to Chlamydia trachomatis then the latter organism assumes an importance at least equal to that of Neisseria gonorrhoeae. A similar situation probably exists in many countries.

There are several broad similarities between $N$ gonorrhoeae and $C$ trachomatis, such as their intracellular habitat and their preference for columnar epithelium. Some clinical aspects are similar also; $C$ trachomatis may cause urethritis,

*Paper presented at the spring meeting of the Medical Society for the Study of Venereal Diseases, Bournemouth, 16-18 May 1980

Address for reprints: Dr O P Arya, University Department of Venereology, Royal Liverpool Hospital, Prescot Street, Liverpool L7 8XP

Accepted for publication 8 September 1980 epididymitis, cervicitis, salpingitis, conjunctivitis, and possibly prostatitis, endocarditis, peritonitis, and perihepatitis. $^{2}$ Despite a wide spectrum of clinicopathological effects a routine laboratory service for culturing $C$ trachomatis is not yet generally available, which probably encourages some workers to continue to regard the "non-specific" genital infection as trivial and which consequently results in a lack of enthusiasm for contact tracing. This attitude is further strengthened by the convenience it affords in assuring and protecting patients from the assumption that their condition was related to sexual indiscretion.

In view of the unlikelihood of a routine laboratory service for $C$ trachomatis being provided in many areas in the immediate future, we have made a search for clinical and epidemiological correlates which might help in the management of the condition in the absence of laboratory diagnosis. A further aim was to establish a baseline of the incidence of chlamydial infections, in a community where contact tracing for non-specific urethritis had not been practised, for future trends and comparisons.

As patients with chlamydia in the genital tract may harbour other sexually transmitted organisms, we considered carefully the influence of intercurrent infections when analysing the data. The clinical and epidemiological findings in women associated with $C$ 
trachomatis compared with $N$ gonorrhoeae and "combined infection", and where relevant Candida albicans and Trichomonas vaginalis, are reported in this paper.

\section{Patients and methods}

The study population comprised 474 women, who had not received an antibiotic in the preceding four weeks, seen by one observer (OPA) at the Special Clinic, St James's Hospital, Birkenhead, between January 1976 and September 1978.

\section{LABORATORY METHODS \\ $N$ gonorrhoeae}

Smears and cultures were made from samples from the urethra and endocervix in all cases and from the rectum in some. Gram-stained smears were examined in the clinic. Swabs sent to the Regional Public Health Laboratory in Stuart's transport medium were cultured on selective media and processed in the usual way.

\section{C trachomatis}

Swabs were taken from the endocervix in all cases and from the urethra in 104 cases. The swabs were transported to the laboratory in $2.5 \mathrm{ml}$ of a transport medium consisting of Wellcome Medium 199 with $0 \cdot 11 \%$ sodium bicarbonate supplemented with $10 \%$ fetal bovine serum, $10 \%$ sorbitol, $0 \cdot 5 \%$ glucose, and 100 units $/ \mathrm{ml}$ each of vancomycin, streptomycin, and mycostatin. The isolation technique was based on that described by Reeve et $a l^{3}$ using idoxuridinetreated McCoy cells. Modifications to the method were the seeding of coverslips with only $6 \times 10^{4}$ McCoy cells: inoculation of only $0.5 \mathrm{ml}$ of specimen together with $1.5 \mathrm{ml}$ of fresh growth medium containing $0.5 \%$ glucose; and staining of infected coverslips after 72 hours' incubation by the Giemsa method of Johnson. ${ }^{4}$

\section{Trichomonas vaginalis}

Wet preparations of material from the posterior vaginal fornix were examined in the clinic by phasecontrast microscopy, and swabs were sent to the laboratory in Feinberg-Whittington medium.

\section{Candida albicans}

Gram-stained vaginal smears were examined for yeast cells and hyphae, and cultures were sent to the laboratory on blood agar.

\section{Herpes simplex virus}

Swabs were taken from the endocervix and sent to the laboratory in virus transport medium to be cultured on human embryonic lung (MRC 5) cells.
A specimen of blood for tests for syphilis was taken in all cases.

\section{STATISTICAL ANALYSIS}

The data were recorded on precoded proformas and analysed with a computer using the Statistical Package for the Social Sciences. Tests of significance were performed using the $\chi^{2}$ method with Yates's correction.

\section{Results}

A total of $\mathbf{4 7 4}$ women was included in the study.

\section{MICROBIOLOGY}

The organisms alone or in combination were isolated as follows: $C$ trachomatis, the commonest organism, was found in $158(33 \cdot 3 \%)$ patients; $N$ gonorrhoeae in $149(31.4 \%)$; $C$ albicans in $88(18 \cdot 6 \%) ; T$ vaginalis in $58(12 \cdot 2 \%)$; and herpes simplex virus in $14(2 \cdot 9 \%)$. In $150(31 \cdot 6 \%)$ patients none of these pathogens was isolated while $130(27 \cdot 4 \%)$ harboured more than one of these organisms.

\section{EPIDEMIOLOGY}

Interrelationship between pathogens

The chlamydial isolation rate in cervical specimens was significantly higher in patients with gonorrhoea but was not affected by the other concurrent infections studied (table I). This higher incidence of chlamydia in patients with gonorrhoea was also apparent (but did not reach significance) in the urethral specimens. Nine (39\%) of 23 patients with gonococci in the urethra, but only $20(25 \%)$ of 81 without, had chlamydia-positive urethral swabs $\left(\chi_{1}^{2}=1 \cdot 21 ; \mathrm{P}>0 \cdot 2\right)$. All of the 29 patients whose urethral specimens were chlamydia-positive harboured the organism in the cervix.

Although $T$ vaginalis and Candida infections showed no correlation with chlamydial isolation rates, patients with gonorrhoea had significantly

TABLE I Chlamydial isolation rates in the presence or absence of other organisms

\begin{tabular}{llrl}
\hline & & \multicolumn{2}{c}{ Chlamydial isolation rate } \\
\cline { 3 - 4 } Concurrent organism & $\begin{array}{l}\text { Total No } \\
\text { of specimens }\end{array}$ & No & $\%$ \\
\hline N gonorrhoeae & 104 & 52 & $50 \cdot 0^{*}$ \\
$C$ albicans & 70 & 18 & $25 \cdot 7$ \\
$T$ vaginalis & 22 & 6 & $27 \cdot 3$ \\
Herpes simplex virus & 5 & 1 & $20 \cdot 0$ \\
Multiple with & & & \\
$\quad N$ gonorrhoeae & 45 & 20 & $44 \cdot 4$ \\
Multiple without & & & \\
$\quad N$ gonorrhoeae & 20 & 3 & $15 \cdot 0$ \\
None & 208 & 58 & $27 \cdot 9 *$ \\
Total & 474 & 158 & $33 \cdot 3$ \\
\hline
\end{tabular}

${ }^{*} \chi^{2}=13 \cdot 90 ; \mathrm{P}<0 \cdot 001$ 
fewer candidal infections and significantly more $T$ vaginalis infections than patients without gonorrhoea. Of the 149 patients with gonorrhoea, nine (6\%) harboured Candida and $32(22 \%) T$ vaginalis, whereas of 325 patients without gonorrhoea 79 (24\%) harboured Candida $(\mathrm{P}<0.001)$ and $26(8 \%) T$ vaginalis $(\mathrm{P}<0 \cdot 001)$.

To eliminate the possibility of bias introduced by these associations (discussed later) the following categories were considered for making comparisons: (A) $N$ gonorrhoeae as the sole pathogen (52 cases); (B) $C$ trachomatis as the sole pathogen (58 cases); (C) combined infection (gonococci and chlamydia as the only pathogens) (52 cases); and (D) no pathogens, serving as a control group (150 cases).

\section{Age}

Of the groups A, B, and C, $57 \cdot 7 \%, 63 \cdot 7 \%$, and $78.9 \%$ respectively were under the age of 25 compared with $51.9 \%$ of those belonging to group D. The difference between those with combined infections (group $C$ ) and no pathogens (group D) was significant $\left(\chi_{1}^{2}=10.41 ; P<0.01\right)$.

\section{Marital state}

There was no significant difference in the proportions of single and married women in the four categories.

\section{Occupation}

Of those with combined infections (group C), 59.6\% were unemployed or in unskilled occupations compared with $40.7 \%$ of those with no pathogens (group D); the difference was significant $\left(\chi_{1}^{2}=4 \cdot 85\right.$; $\mathrm{P}<0 \cdot 05)$.

\section{Past history of gonorrhoea}

No significant differences were found among the four categories.

\section{Last exposure}

Significantly fewer $(24 \cdot 1 \%)$ of those with chlamydia (group B) had had sexual intercourse during the preceding week than those with gonorrhoea (group $A, 48 \cdot 1 \%$ ) or those with no pathogens (group D, $44.7 \%)\left(\chi^{2}=5.86\right.$ and $6.57 ; \mathrm{P}<0.02$ and $<0.02$ respectively). The rate among those with combined infections (group C) was $33 \%$.

\section{Previous exposure}

Information about recent previous sexual exposure to another (other than the regular) partner was available for 277 patients. Of the 44 with gonorrhoea and of the 45 with combined infections $25 \%$ and $22 \cdot 2 \%$ respectively had had sexual intercourse with another partner during the previous four weeks com- pared with only $8 \cdot 1 \%$ of the 135 without pathogens $\left(\chi_{1}^{2}=7 \cdot 25\right.$ and $5 \cdot 19 ; \mathrm{P}<0.01$ and $<0.05$ respectively) and $9.4 \%$ of the 53 with chlamydia only.

\section{Oral contraceptives}

Of those in groups A, B, and C, $49 \%, 81 \cdot 5 \%$, and $67 \cdot 3 \%$ respectively were taking an oral contraceptive compared with $55.8 \%$ in group D. Only the difference between those with chlamydia (group B) and those with no pathogens (group D) was significant $\left(\chi_{1}^{2}=10.07 ; \mathrm{P}<0.01\right)$.

\section{Menstruation}

Chlamydial isolation was not significantly affected by the stage of the menstrual cycle.

FEMALE CONSORTS OF MEN WITH URETHRITIS Gonococcal and chlamydial isolation

$C$ trachomatis was isolated from $64(49 \%)$ of 130 consorts of men with gonorrhoea (56 of these 64 chlamydia-positive women also harboured gonococci); from $52(43 \%)$ of 121 consorts of men with nongonococcal urethritis (NGU); from seven (50\%) of 14 consorts of men with presumptive urethritis (that is, men who were alleged to have attended a special clinic and had been treated with tablets or injection); from 27 (17\%) of 158 consorts of men on whom no information about urethritis was available; and from eight $(13 \%)$ of 61 consorts of men who had no urethritis. The difference between the chlamydial isolation rate in consorts of men with urethritis and in consorts whose male partners did not have urethritis was significant $(\mathrm{P}<0 \cdot 001)$.

Thirty-one $(72 \%)$ female consorts of 43 chlamydia-positive men with NGU harboured $C$ trachomatis in the cervix compared with eight $(22 \%)$ consorts of 36 chlamydia-negative men with NGU: the difference was significant $\left(\chi_{1}^{2}=17 \cdot 55 ; \mathrm{P}<0 \cdot 001\right)$. Twenty-three $(\mathbf{7 4 \%})$ female consorts of 31 men with combined infections harboured both chlamydia and gonococci.

The chlamydial and gonococcal isolation rates in female consorts of men with urethritis are given in table II according to the type of consort (primary, secondary, or unknown) and to the organisms associated with the man's urethritis. Isolation rates of $100 \%$ were found in women who were primary contacts, but the chlamydial isolation rate of $52 \%$ among the secondary contacts was lower than the gonococcal isolation rate of $81 \cdot 2 \%$ among the corresponding secondary contacts.

\section{CLINICAL FEATURES}

\section{Interrelationship between pathogens}

Of 16 women infected with $T$ vaginalis only and of 52 infected with Candida only, $62 \cdot 5 \%$ and $69 \cdot 2 \%$ 
TABLE II Isolation rates for $C$ trachomatis and $N$ gonorrhoeae in female partners of men with urethritis according to the type of sexual contact and infective agent in men

\begin{tabular}{|c|c|c|c|c|}
\hline \multirow[b]{2}{*}{ Type of contact } & \multicolumn{4}{|c|}{ Infective agents (men)। and No of female partners infected: } \\
\hline & $\begin{array}{l}N \text { gonorrhoeae } \\
\text { (28) }\end{array}$ & $\begin{array}{l}\text { C trachomatis } \\
\text { (43) }\end{array}$ & $\begin{array}{l}\text { Both } \\
\text { (3I) }\end{array}$ & $\begin{array}{l}\text { NGU/no chlamydia } \\
\text { (36) }\end{array}$ \\
\hline \multicolumn{5}{|l|}{ Primary contact } \\
\hline Total & 6 & 8 & 6 & 17 \\
\hline Gonococci & 4 & 0 & 0 & 1 \\
\hline Chlamydia & 0 & 7 & 0 & 3 \\
\hline Both & 2 & 1 & 6 & 0 \\
\hline Isolation rate $(\%)$ & $100(\mathrm{G})$ & $100(\mathrm{C})$ & $100(G+C)$ & \\
\hline \multicolumn{5}{|l|}{ Secondary contact } \\
\hline Total & 16 & 25 & 18 & 10 \\
\hline Gonococci & 9 & 0 & 4 & 0 \\
\hline Chlamydia & 0 & 12 & 1 & 1 \\
\hline Both & & 1 & & 0 \\
\hline Isolation rate $(\%)$ & $81 \cdot 2(\mathrm{G})$ & $52 \cdot 0(\mathrm{C})$ & $66 \cdot 7(G+C)$ & \\
\hline \multicolumn{5}{|l|}{ Status unknown } \\
\hline Total & 6 & 10 & 7 & 9 \\
\hline Gonococci & 3 & $\mathbf{0}$ & 2 & 0 \\
\hline Chlamydia & 0 & 10 & 0 & 4 \\
\hline Both & 1 & 0 & 5 & 0 \\
\hline Isolation rate $(\%)$ & $66 \cdot 7(\mathrm{G})$ & $100(\mathrm{C})$ & $71 \cdot 4(\mathrm{G}+\mathrm{C})$ & \\
\hline \multicolumn{5}{|l|}{ Grand total } \\
\hline Total & 28 & 43 & 31 & 36 \\
\hline Gonococci & 16 & 0 & 6 & 1 \\
\hline Chlamydia & 0 & 29 & 1 & 8 \\
\hline Both & 7 & 2 & 23 & 0 \\
\hline Isolation rate $(\%)$ & $82 \cdot 1(G)$ & $72 \cdot 1(\mathrm{C})$ & $74 \cdot 2(G+C)$ & \\
\hline
\end{tabular}

$\mathbf{G}=$ gonococci

$\mathrm{C}=$ chlamydia

respectively complained of vaginal discharge or irritation or both compared with $17(32 \cdot 6 \%)$ and 21 $(36 \cdot 2 \%)$ respectively of those harbouring gonococci and chlamydia. The differences between those with Candida and those with gonorrhoea, and between those with Candida and those with chlamydia, were significant $\left(\chi_{1}^{2}=12 \cdot 47\right.$ and $10 \cdot 69 ; \mathrm{P}<0 \cdot 001$ and $<0.01$ respectively). When compared with the group with no pathogens (group D) $T$ vaginalis infection was significantly associated with vaginal discharge $\left(34 / 150\right.$ and $8 / 16$ respectively; $\left.\chi_{1}^{2}=4 \cdot 36 ; \mathrm{P}<0 \cdot 05\right)$ Hence, patients with Candida and $T$ vaginalis must be excluded when the clinical features of chlamydial and gonococcal infections are studied. Hence the same four categories defined above are retained here.

\section{Symptoms}

Thirty-five $(67 \cdot 3 \%), 37(63 \cdot 8 \%)$, and $31(59 \cdot 6 \%)$ respectively of those with gonococci, chlamydia, and combined infections were asymptomatic compared with $78(52 \%)$ of those with no pathogens; the differences were not significant. The complaint of vaginal discharge was also almost equally common among all the four groups (range $21 \cdot 1-26 \cdot 9 \%$ ).

Fifty-two patients had urinary symptoms and there was no difference in this respect among the four groups.

\section{Signs}

Cervical ectopy. Chlamydia, whether in the presence or absence of gonococci, were found significantly more often in patients with cervical ectopy (table III). No such association with ectopy was found in those infected with gonorrhoea, Candida, or $T$ vaginalis.

Interrelationship between oral contraception, cervical ectopy, and chlamydial isolation. Of the $\mathbf{2 7 4}$ women who were taking an oral contraceptive, 151 $(55 \cdot 1 \%)$ had cervical ectopy compared with 56 $(30.4 \%)$ of 184 who were not; the difference was significant $\left(\chi_{1}^{2}=26.07 ; P<0 \cdot 001\right)$. We had noted earlier (see above) a significant association between the use of an oral contraceptive and the isolation of chlamydia. It was, therefore, necessary to examine the effect of oral contraceptives and cervical ectopy independently of each other on the chlamydial isolation rate. (Patients with concomitant infections were excluded.) The results were:

(a) If no oral contraceptive was used and cervical ectopy absent, $C$ trachomatis was isolated in none of 53 patients;

(b) If a contraceptive was used and cervical ectopy absent, $C$ trachomatis was isolated in 14 $(23 \cdot 7 \%)$ of 59 patients; 
TABLE III Presence or absence of cervical ectopy in relation to isolation of infective agents

\begin{tabular}{|c|c|c|c|c|c|c|c|c|c|c|c|c|c|}
\hline \multirow{2}{*}{ Ectopy } & \multirow{2}{*}{ Total } & \multicolumn{12}{|c|}{ No of women harbouring: } \\
\hline & & \multicolumn{2}{|c|}{ Gonococci } & \multicolumn{2}{|c|}{ Chlamydia } & \multicolumn{2}{|c|}{ Both organisms } & \multicolumn{2}{|c|}{ Candida } & \multicolumn{2}{|c|}{ Trichomonads } & \multicolumn{2}{|c|}{ No pathogen } \\
\hline $\begin{array}{l}\text { Present } \\
\text { Absent } \\
\text { Total }\end{array}$ & $\begin{array}{l}170 \\
210 \\
380\end{array}$ & $\begin{array}{l}18 \\
34 \\
52\end{array}$ & $\begin{array}{l}34 \cdot 6 \\
65 \cdot 4 \\
100\end{array}$ & $\begin{array}{l}42 \\
16 \\
58\end{array}$ & $\begin{array}{l}72 \cdot 4 \\
27 \cdot 6 \\
100\end{array}$ & $\begin{array}{l}36 \\
16 \\
52\end{array}$ & $\begin{array}{l}69 \cdot 2 \\
30 \cdot 8 \\
100\end{array}$ & $\begin{array}{l}15 \\
37 \\
52\end{array}$ & $\begin{array}{l}28 \cdot 9 \\
71 \cdot 1 \\
100\end{array}$ & $\begin{array}{r}9 \\
7 \\
16\end{array}$ & $\begin{array}{l}56 \cdot 3 \\
43 \cdot 7 \\
100\end{array}$ & $\begin{array}{r}50 \\
100 \\
150\end{array}$ & $\begin{array}{l}33 \cdot 3 \\
66 \cdot 7 \\
100\end{array}$ \\
\hline
\end{tabular}

Chlamydia vs no pathogen: $\chi^{2}=24 \cdot 34 ; \mathrm{P}<0 \cdot 001$

Gonococci and chlamydia $v s$ no pathogen: $\chi^{2}=18.91 ; P<0.001$

(c) If no oral contraceptive was used and cervical ectopy was present, $C$ trachomatis was isolated in $10(45 \cdot 5 \%)$ of 22 patients; and

(d) If an oral contraceptive was used and cervical ectopy was present, $C$ trachomatis was isolated in $30(44 \cdot 8 \%)$ of 67 patients.

Cervical discharge. Mucopurulent discharge in the endocervix was seen in $23.1 \%$ of those with gonococci, $22.4 \%$ of those with chlamydia, and $30.8 \%$ of those with combined infection compared with only $4 \%$ of those with no pathogens. The difference between each infected group and group $D$ was significant $\left(\chi_{1}^{2}=15 \cdot 68,14 \cdot 62\right.$, and $24 \cdot 74 ; \mathrm{P}<0 \cdot 001$ in each case). Of those infected with $T$ vaginalis, $18 \cdot 7 \%$ also had a mucopurulent discharge in the endocervix.

Cervicitis. Using Paavonen's criterion ${ }^{5}$ (congested cervix and hypertrophic ectopy usually associated with mucopus) cervicitis was found in $23(39.6 \%)$ of 58 cases infected with chlamydia and $19(36.5 \%)$ of 52 with combined infections compared with only 20 $(13.3 \%)$ of 150 in group $D$. The difference was significant in each case $\left(\chi_{1}^{2}=16 \cdot 10\right.$ and $11 \cdot 89$; $P<0.001$ and $<0.001)$. But the difference between those with gonococci $(21 \cdot 1 \%$ with cervicitis) and group D was not significant.

Salpingitis. Using diagnostic criteria based on those of Simmons et $a l^{6}$ eight patients were considered to have salpingitis; two harboured chlamydia only, four gonococci only, and the remaining two both chlamydia and gonococci.

\section{Discussion}

The pattern of significant association between the isolation of $N$ gonorrhoeae and $C$ trachomatis but not between the presence of chlamydia, Candida, and $T$ vaginalis was strikingly similar to that reported by Hilton et al. ${ }^{7}$ This association seemed even more remarkable in the absence of cervical ectopy, with $32 \%$ of women being chlamydia-positive in the presence of gonococci compared with only $13.8 \%$ without (table III; $\chi_{1}^{2}=6 \cdot 32 ; \mathrm{P}<0 \cdot 02$ ). We also found a significant negative association between $N$ gonorrhoeae and $C$ albicans and a positive association between $N$ gonorrhoeae and $T$ vaginalis. Whether these associations and others, such as a high coincidence of chlamydial infection with $T$ vaginalis noted by Kinghorn and Waugh ${ }^{8}$ and Tait et al, ${ }^{9}$ act in an inhibitory or symbiotic way is not clear. In addition, $C$ albicans and $T$ vaginalis, although predominantly infecting the vagina, may cause erythema of the ectocervix and an ectocervicitis or endocervicitis respectively. ${ }^{10-12}$ These associations are therefore, potentially capable of introducing bias; thus the study of epidemiological and clinical features must (as in this paper) be related separately to pathogens existing singly or in specified combinations. This fact must also be borne in mind when comparisons with other studies are made.

We found that cervicitis was more frequently associated with chlamydial than with gonococcal infection. As also observed by Rees, ${ }^{13}$ cervicitis in several cases with combined infections (chlamydia and gonococci) persisted after treatment of gonorrhoea with spectinomycin or single-dose regimens of penicillin (postgonococcal cervicitis) (Arya et al, unpublished data).

Apart from the association with $N$ gonorrhoeae, the most outstanding correlates of chlamydial infection were the use of an oral contraceptive and cervical ectopy-acting independently of each other-but cervical ectopy had the more dominating influence since in its presence the addition of an oral contraceptive did not make any difference to the chlamydial isolation rate. These findings were at variance with those of Tait $e t a l^{9}$ in their study of female contacts of men with NGU. Oral contraceptives may produce microscopic and macroscopic changes in the cervix ${ }^{14}$-namely, hyperplasia and hypersecretion of the cervical glands, enlargement of columnar villi, hyperaemia and oedema of the columnar epithelium, and eversion of the endocervix. Some of these changes, especially in the presence of ectopy (which is simply an extension of the 
endocervical epithelium), may provide a favourable environment for infection by $C$ trachomatis.

Our finding that $N$ gonorrhoeae was not significantly associated with cervical ectopy may possibly suggest that columnar epithelium is not an important requirement for infection by this organism. Indeed, Evans ${ }^{15}$ in his ultrastructural study of cervical gonorrhoea found gonococci to be firmly attached to stratified squamous epithelium and not to the mucus-secreting columnar epithelium.

The $100 \%$ isolation rates of $N$ gonorrhoeae, $C$ trachomatis, and both organisms in patients with combined infections among the primary consorts of men infected with the corresponding organism(s) was to be expected and showed our accurate identification of contacts, which is not always possible, however. The lower isolation rate of $C$ trachomatis than of $N$ gonorrhoeae among the secondary contacts would be expected if $N$ gonorrhoeae was more infectious than $C$ trachomatis (suggested recently by Lycke et $a l^{16}$ ). However, transmission of infection can be influenced by the organism and by the host, and an important consideration here, among other determinants, must be the presence of cervical ectopy in the potential recipients.

\section{Clinical conclusions}

In this study 158 cases of chlamydial infection were identified, and one of the aims was to find correlates which might help in the management of these cases in the absence of laboratory facilities. As gonococcal infection is often accompanied by non-specific or chlamydial infection it has been proposed that gonorrhoea should be treated with a regimen which will be effective against both conditions. ${ }^{17}$ In our study of 474 women this suggestion would have led to the treatment of 72 of the 158 chlamydia-positive patients but also to treating unnecessarily 77 patients who had gonorrhoea but no chlamydial infection. A further eight chlamydia-positive patients would have been recognised and similarly treated if 20 women who were consorts of men with gonorrhoea, but themselves without gonorrhoea, had been treated epidemiologically.

It has also been proposed that all female consorts of men with NGU should be treated on epidemiological grounds, ${ }^{18}$ which would have included 48 further cases of chlamydial infection in our population by treating a further 114 women. We would then have been left with 30 cases of chlamydial infection out of the remaining total of 191 women who were not known to be contacts of men with urethritis. How could these cases (and their contacts) be identified? As shown earlier, age, marital state, occupation, symptoms, and past history of gonorrhoea by themselves were unhelpful indices. However, among the remaining 191 women were 69 who did not have cervical ectopy and were not taking an oral contraceptive, and only one of these was chlamydiapositive. In contrast there were 15 chlamydia-positive patients among the 46 who had both cervical ectopy and were using an oral contraceptive. Only three of these 15 chlamydia-positive patients had cervicitis. Unfortunately, therefore, the predictive value of all the clinical and epidemiological indices studied, even when used in combination, remains unacceptably low. Thus the 30 cases (mentioned above), constituting $15 \cdot 7 \%$ of the 191 women, might not have been treated (a figure very similar to $12 \%$ reported recently by Richmond et al). ${ }^{19}$

Even if laboratory facilities for chlamydial isolation become available, there will still be about the same number of cases, as those infected with $C$ trachomatis, of non-specific genital infection which will remain unidentified and untreated (compare: half of the cases of NGU in men whose aetiology remains unknown). For female patients the answer lies in the provision of a laboratory service for chlamydial isolation as well as treatment of consorts of men with urethritis; otherwise these infections may continue unchecked.

We are indebted to Dr S S Pareek, Nursing Sister L Jones, and Staff Nurses $R$ Evans and $J$ Davey for their invaluable help. We also thank the staff of the Liverpool Regional Public Health Laboratory for gonococcal culture and the serological tests for syphilis, the Microbiology Laboratory of St Catherine's Hospital for the other microbiological investigations, and the Mersey Regional Health Authority for financial support.

\section{References}

1. Department of Health and Social Security. Sexually transmitted diseases. Annual Report of the Chief Medical Officer, 1978. London: HMSO, 1979.

2. Taylor-Robinson D, Thomas BJ. The role of Chlamydia trachomatis in genital tract and associated diseases. $J$ Clin Pathol 1980; 33:205-33.

3. Reeve P, Owen J, Oriel JD. Laboratory procedures for the isolation of Chlamydia trachomatis from the human genital tract. J Clin Pathol 1975;28:910-4.

4. Johnson FWA. A comparison of staining techniques for demonstrating group A Chlamydia in tissue culture. Medical Laboratory Technology 1975; 32:233-8.

5. Paavonen J. Chlamydia trachomatis-induced urethritis in female partners of men with nongonococcal urethritis. Sex Transm Dis 1979; 6:69-71.

6. Simmons PD, Forsey $\mathrm{T}$, Thin RN, et al. Antichlamydial antibodies in pelvic inflammatory disease. $\mathrm{Br} J$ Vener Dis 1979; 55:419-21.

7. Hilton AL, Richmond SJ, Milne JD, Hindley F, Clarke SKR. Chlamydia A in the female genital tract. Br J Vener Dis 1974; 50: $1-10$.

8. Kinghorn GR, Waugh MA. Non-specific genital infection. $\mathbf{B r}$ Med J 1979; ii: 441 . 
9. Tait IA, Rees E, Hobson D, Byng RE, Tweedie MCK Chlamydial infection of the cervix in contacts of men with nongonococcal urethritis. Br J Vener Dis 1980;56:37-45.

10. Oriel JD, Powis PA, Reeve P, Miller A, Nicol CS. Chlamydial infections of the cervix. Br J Vener Dis 1974; 50:11-6.

11. Jordan JA, Singer A (eds). The Cervix. London: WB Saunders. 1976:259.

12. Coppleson M, Reid B, Pixley E. Preclinical Carcinoma of the Cervix Uteri. London: Pergamon Press, 1967;56.

13. Rees $\mathbf{E}$. Treatment and management of pelvic inflammatory disease. Am J Obstet Gynecol 1980; 138: 1042-7.

14. Jordan JA, Singer A (eds). The Cervix. London: WB Saunders. 1976: 193.
$O$ P Arya, $H$ Mallinson, and A D Goddard

15. Evans BA. Ultrastructural study of cervical gonorrhoea. $J \overparen{\mathbb{D}}$ Infect Dis 1977; 136:248-55.

16. Lycke E, Lowhagen G, Hallhagen G, Johannisson G, Ramstedt K. The risk of transmission of genital Chlamydia ? trachomatis infection is less than that of genital Neisseria gonorrhoeae infection. Sex Transm Dis 1980;7:6-10.

17. Willcox RR. Epidemiological importance of concealed nongonococcal urethritis. Br J Vener Dis 1979; 55: 149-53.

18. Anonymous. Non-specific genital infection. Br Med J 1979; ii 161-2.

19. Richmond SJ, Paul ID, Taylor PK. Value and feasibility of screening women attending STD clinics for cervical chlamydial infections. Br J Vener Dis 1980; 56:92-5. 